Article

\title{
Relative Validity and Reproducibility of a Food Frequency Questionnaire to Assess Nutrients and Food Groups of Relevance to the Gut Microbiota in Young Children
}

\author{
Claudia Leong ${ }^{1,2,3}{ }^{\oplus}$, Rachael W. Taylor ${ }^{2}$, Jillian J. Haszard ${ }^{1}{ }^{\circ}$, Elizabeth A. Fleming ${ }^{1}$, \\ Gerald W. Tannock ${ }^{4,5}$, Ewa A. Szymlek-Gay ${ }^{6}{ }^{\circledR}$, Sonya L. Cameron ${ }^{1}$, Renee Yu ${ }^{1}$, Harriet Carter ${ }^{1}$, \\ Li Kee Chee ${ }^{1}$, Lucy Kennedy ${ }^{1}$, Robyn Moore ${ }^{1}$ and Anne-Louise M. Heath ${ }^{1,3,5, * \mathbb{D}}$ \\ 1 Department of Human Nutrition, University of Otago, P.O. Box 56, Dunedin 9054, New Zealand; \\ leocl333@student.otago.ac.nz (C.L.); jill.haszard@otago.ac.nz (J.J.H.); liz.fleming@otago.ac.nz (E.A.F.); \\ sonyalcameron@gmail.com (S.L.C.); yure1721@student.otago.ac.nz (R.Y.); \\ carha847@student.otago.ac.nz (H.C.); cheli159@student.otago.ac.nz (L.K.C.); \\ lucykennedy@hotmail.co.nz (L.K.); mooro526@student.otago.ac.nz (R.M.) \\ 2 Department of Medicine, Dunedin School of Medicine, University of Otago, P.O. Box 56, \\ Dunedin 9054, New Zealand; rachael.taylor@otago.ac.nz \\ 3 Nutrition Society of New Zealand, P.O. Box 2039, Whanganui 4543, New Zealand \\ 4 Department of Microbiology and Immunology, University of Otago, P.O. Box 56, \\ Dunedin 9054, New Zealand; gerald.tannock@otago.ac.nz \\ 5 Microbiome Otago, University of Otago, P.O. Box 56, Dunedin 9054, New Zealand \\ 6 Institute for Physical Activity and Nutrition (IPAN), School of Exercise and Nutrition Sciences, \\ Deakin University, Geelong, VIC 3220, Australia; ewa.szymlekgay@deakin.edu.au \\ * Correspondence: anne-louise.heath@otago.ac.nz; Tel.: +64-3-479-8379
}

Received: 7 October 2018; Accepted: 22 October 2018; Published: 2 November 2018

check for updates

\begin{abstract}
Dietary fiber is an important nutrient for the gut microbiota, with different fiber fractions having different effects. The aim of this study was to determine the relative validity and reproducibility of a food frequency questionnaire (EAT5 FFQ) for measuring intake of fiber, and low and high fiber foods, in studies examining diet and gut microbiota in young children. One hundred parents of 5-year old children completed the 123-item EAT5 FFQ on two occasions four weeks apart. A 3-day weighed diet record (WDR) was completed on non-consecutive days between FFQ appointments. Mean correlations between the (randomly chosen) FFQ and WDR were acceptable for nutrient and food group intakes ( $r=0.34$ and $r=0.41$ respectively). Gross misclassification was below chance (12.5\%) for quartiles of nutrient (mean 5.7\%) and food group (mean 5.1\%) intake. 'Absolute values for surrogate categories' suggested the FFQ clearly differentiated between highest and lowest quartiles for all nutrients and food groups tested. Mean correlations between repeat administrations of the FFQ suggested very good reproducibility for nutrients $(r=0.83)$ and food groups $(r=0.80)$. The EAT5 FFQ appears to be an appropriate tool for investigating the intake of nutrients and food groups of relevance to the gut microbiota, and is the first FFQ validated to measure total, soluble and insoluble non-starch polysaccharide intakes in young children.
\end{abstract}

Keywords: food frequency questionnaire; dietary fiber; microbiota; validity; reproducibility; children; New Zealand 


\section{Introduction}

A rapidly expanding literature suggests that the gut microbiota may have beneficial or harmful impacts on health [1,2]. Diet plays an important role in modulating gut microbiota, although much of this work has been in adults with little research undertaken in children [3,4]. A dietary component of particular interest is dietary fiber, as it is the main food source for the gut microbiota $[5,6]$. Because different classes (soluble, insoluble) or fractions (e.g., arabinoxylan from whole grains, pectin from fruits, and cellulose from vegetables) of fiber appear to impact gut microbiota in different ways [7-10], appropriate dietary assessment techniques must be used to improve understanding of how diet influences the microbiota and subsequent health outcomes. While weighed diet records (WDR) or 24-h recalls are generally considered gold standard methods of dietary assessment [11], they entail considerable respondent and researcher burden, and do not directly assess 'usual' intake. Food frequency questionnaires (FFQ) have lower respondent burden, estimate usual intake, and can be used in larger studies examining the long-term effects of diet on the gut microbiota. However, the validity of any new FFQ must be determined in order to ensure that it adequately measures the nutrients of interest in the relevant population [12].

In addition to investigating intake of nutrients, such as dietary fiber, it is also important to be able to determine intake of foods. Most foods are complex combinations of multiple nutrients and food components that cannot be captured by simply measuring nutrient intake, we eat foods rather than nutrients, and dietary guidelines refer to foods rather than nutrients [12].

To date, no studies have validated an FFQ specifically designed to look at both nutrients and food groups of relevance to the gut microbiota, specifically dietary fiber [9], soluble and insoluble non-starch polysaccharides (NSP) [7,8], and food groups that are high and low in fiber. Therefore, the aim of this study was to determine the relative validity and reproducibility of the EAT5 FFQ for estimating intake of both nutrients and food groups of relevance to the gut microbiota in 5-year old New Zealand children.

\section{Materials and Methods}

\subsection{Study Design}

The study was designed to validate the EAT5 FFQ for measuring intake of nutrients (energy, carbohydrate, fiber, total NSP, soluble NSP, and insoluble NSP) and food groups (e.g., 'Higher fiber more healthy cereals', 'Higher fiber less healthy cereals', 'Lower fiber more healthy cereals', 'Lower fiber less healthy cereals', 'Nuts and legumes', 'Fruits', 'Vegetables', 'Potatoes and hot chips', 'Yoghurt'). Parent and child participants attended two appointments four weeks apart. At the first appointment, the EAT5 FFQ and socio-demographic questionnaire were completed by the parents, and anthropometric measurements of the child were obtained. A 3-day WDR was completed over the following four weeks. At the second appointment, the EAT5 FFQ was administered again so that reproducibility could be assessed. The FFQs asked about intake in the past month.

\subsection{Participants}

A convenience sample of 100 participants (parent-child pairs) was recruited from Dunedin, Auckland and Wellington (New Zealand) from February 2015 to December 2017. The child had to be healthy and aged $\geq 5$ to $\leq 6$ years during the time of assessment to be eligible for the study. The study was conducted in accordance with the Declaration of Helsinki. The Human Ethics Committee of the University of Otago, Dunedin, New Zealand, granted ethical approval for the study (reference number H14/154). Written informed consent was obtained from all parents and children.

Parents completed a questionnaire on their child's age, sex, ethnicity and number of siblings. Using the participants' home address, the NZDep2013 Index of Deprivation was determined (range from 1 to 10, with a value of 1 representing the least deprived $10 \%$ of New Zealand households, and a value of 10 representing the $10 \%$ most deprived) [13]. The child's height and weight were 
measured using standard protocols [14]. Height was measured using a Leicester wall stadiometer (Tanita, IL, USA) to the nearest $0.1 \mathrm{~cm}$, with duplicate measures taken (and a third measurement if duplicates were not within $0.7 \mathrm{~cm}$ of each other). Weight was measured using digital scales (Seca Alpha model 770; Seca, Hamburg, Germany) to the nearest $0.1 \mathrm{~kg}$, with duplicate measures taken (and a third measurement if duplicates were not within $0.1 \mathrm{~kg}$ of each other). Body mass index (BMI) was calculated from the average of height and weight measurements using the formula: weight in kilograms divided by height in meters squared.

\subsection{EAT5 Food Frequency Questionnaire}

The EAT5 FFQ was designed to be quantitative, interviewer administered and to rank 5-year old children by intake over the past month of nutrients of relevance to the gut microbiota, with data collected from the primary caregiver (usually a parent). The EAT5 FFQ was a modified version of the previously validated EAT FFQ designed to assess nutrient intake [15] and dietary patterns [16] in New Zealand toddlers aged 12-24 months, which was in turn originally based on the Southampton Women's Survey questionnaire for infants [17]. For the EAT5 FFQ, the EAT food list was reconstructed to remove infant foods and to include a wider variety of fruit and vegetable food items in order to better differentiate between fiber fractions (e.g., soluble vs. insoluble NSPs). Three important components were present in the EAT5 FFQ: (i) cross-check questions for fruit and vegetable intake; (ii) use of volume for the amount eaten for foods that did not have a natural portion size (e.g., 'slice') with participants demonstrating volumes consumed using dried beans and rice on plates, bowls and cups; and (iii) a wide variety of fruit and vegetable food items-14 and 18 food items respectively. The cross-check question asked parent participants the overall frequency of their child's fruit (or vegetable) consumption over the past month, so that the frequency of each individual item within the fruit (or vegetable) section could be weighted to adjust for the overall frequency (i.e., 'fruit and vegetable adjusted' frequency) [18]. The EAT5 FFQ fruit (or vegetable) weighting factor was calculated as follows: 'frequency from cross-check question' divided by 'sum of frequencies from the fruit (or vegetable)'. The weighting factor was then applied to the frequency for each fruit (or vegetable) item to get the 'fruit and vegetable adjusted' frequency value for that individual fruit (or vegetable) item. This was undertaken to account for the well-established overestimation in fruit and vegetable intake that can occur when participants estimate and report consumption frequency for multiple individual fruits and vegetables [19,20].

The EAT5 FFQ asked about intakes over the past month using 10 frequency-response options, ranging from 'not eaten this month' to an open-ended question for multiple times per day. The EAT5 FFQ comprised 123 food items under 11 section headings: (i) bread, crackers and breakfast cereals; (ii) rice and pasta; (iii) fruits; (iv) vegetables; (v) meat, chicken, fish, eggs, beans; (vi) spreads; (vii) cakes, biscuits, snacks; (viii) milk and dairy products; (ix) puddings; (x) drinks; (xi) takeaways. The EAT5 FFQ is available upon request from the corresponding author.

Nutrient intakes were calculated using FOODfiles 2014 [21], except for NSP values where FOODfiles 2010 [22] was used because these data were not available for all foods in FOODfiles 2014. Some of the 123 food items had multiple foods in the same food item question. For these food items, the nutrient composition of the individual foods was weighted using age-appropriate frequency and portion size consumption data $[23,24]$.

\subsection{Weighed Diet Record}

Parents completed a 3-day WDR on 3 randomly assigned, non-consecutive days (1 weekend day and 2 week days) over four weeks. Participants were given detailed verbal and written instructions and a calibrated electronic kitchen scale (Salter Vista, Kent, UK; $\pm 1 \mathrm{~g}$ ) at the first visit and then contacted during the collection period so that they could ask further questions. On the second visit, the WDR was collected and checked by trained staff. Diet records were analyzed with the Kai-culator nutritional software package version 1.16a (Department of Human Nutrition, University of Otago, New Zealand) 
using the nutrient database FOODfiles 2014 [21], except for NSP values where FOODfiles 2010 [22] was used.

\subsection{Food Groups}

The 123 food items in the EAT5 FFQ were assigned to 12 food groups that were defined based on food groups of relevance to the gut microbiota $[4,7,25,26]$, and the number of consumers (i.e., at least 8 consumers were required in each food group so that there would be sufficient power to perform the food group analyses [27]). Food items were allocated to the food groups based on nutrient profile and similarity of use (Figure 1). The same 12 food groups were used for the 3-day WDR data. In total, 1010 individual food items were entered into Kai-culator from the WDRs. These 1010 individual food items were allocated to the 12 food groups, except for water, which was excluded.

\begin{tabular}{|c|c|}
\hline Food Group & EAT5 Food Frequency Questionnaire Food Item \\
\hline $\begin{array}{l}\text { Higher fiber }(\geq 3.4 \\
\mathrm{g} / 100 \mathrm{~g}) \text { more healthy } \\
\text { cereals * }\end{array}$ & $\begin{array}{l}\text { Wholegrain bread or bun, Wholemeal bread or bun, White buns, Pizza (not takeaway), } \\
\text { Crackers (wheat, rice or corn-based), Rice cakes or rice wheels, Cruskits or crispbreads, } \\
\text { Weet-bix }\end{array}$ \\
\hline $\begin{array}{l}\text { Higher fiber }(\geq 3.4 \\
\mathrm{g} / 100 \mathrm{~g}) \text { less healthy } \\
\text { cereals * }\end{array}$ & $\begin{array}{l}\text { Fruity-bix or similar, Muesli and light muesli, Other breakfast cereal, Fruit bread, } \\
\text { Currant buns, Muesli or nut or cereal or puffed rice bars, Crisps, Corn chips, Corn } \\
\text { snacks (eg. Cheezels) }\end{array}$ \\
\hline $\begin{array}{l}\text { Lower fiber more } \\
\text { healthy cereals* }\end{array}$ & $\begin{array}{l}\text { White bread, White rice, Instant noodles, Canned spaghetti, Other pasta (not including } \\
\text { sauce), Brown rice, Porridge, Cornflakes or rice bubbles }\end{array}$ \\
\hline $\begin{array}{l}\text { Lower fiber less } \\
\text { healthy cereals * }\end{array}$ & $\begin{array}{l}\text { Cocopops, Honey puffs or puffed wheat cereal, Nutrigrain, Milo cereal or similar, } \\
\text { Biscuits - chocolate coated, Biscuits - other, Cakes or slices, Muffins or scones, Croissant, } \\
\text { Sweet buns, Iced buns, Pastries, Puddings not yet described }\end{array}$ \\
\hline Nuts and legumes & $\begin{array}{c}\text { Hummus (chickpea dip), Baked beans, Canned or home cooked beans, Chickpeas or } \\
\text { lentils, Peanut butter, Nuts (any sort but not peanut butter) }\end{array}$ \\
\hline Fruits & $\begin{array}{l}\text { Apples (fresh or canned), Pears, Banana, Raisins or sultanas, Dried apricots or prunes, } \\
\text { Apricots, Plums, Peaches, Oranges, Mandarins, Kiwifruit, Green grapes, Black or red } \\
\text { grapes, Berries or cherries, Avocado, Rhubarb, Other fruit }\end{array}$ \\
\hline Vegetables & $\begin{array}{c}\text { Yams, Carrot, Pumpkin, Green peas, Green beans, Sweet corn, Broccoli, Cauliflower, } \\
\text { Capsicum (peppers), Red cabbage, Green cabbage, Spinach or silverbeet, Lettuce or } \\
\text { salad leaves, Cucumber, Raw tomato, Cooked tomato (pasta sauce, canned tomatoes, } \\
\text { tomato sauce), Leeks, Other vegetables }\end{array}$ \\
\hline Potatoes and hot chips & $\begin{array}{l}\text { Potato salad or other potato eaten cold, Potato or kumara (boiled, baked, microwaved, } \\
\text { mashed) eaten warm or hot, Hot chips, Potato shapes, Roast potato or kumara cooked at } \\
\text { home eaten warm or hot, Chips from a takeaway shop or fast food restaurant }\end{array}$ \\
\hline Dairy & $\begin{array}{l}\text { Cow's milk as a drink, Cow's milk on cereal or other food, Low-fat cow's milk as a } \\
\text { drink, Low-fat cow's milk on cereal or other food, Cheese (including in recipes), White } \\
\text { sauce or cheese sauce, Cream or sour cream, Ice cream, Custard and other milk } \\
\text { puddings, Flavored milk (including Milo, Quick, Dinking chocolate, Up-and-Go) }\end{array}$ \\
\hline Yoghurt & Yoghurt or dairy food \\
\hline Meat, fish, egg & $\begin{array}{l}\text { Eggs, Mince \& patties (from beef or lamb), Steak, Chops or roast (beef or lamb), Fish } \\
\text { (e.g., canned, pan-fried), Chicken (eg., roast, stir-fry, barbeque, Pork and other meat, } \\
\text { Sausages, saveloys, Ham, Bacon, Luncheon, Salami }\end{array}$ \\
\hline Miscellaneous & $\begin{array}{l}100 \% \text { orange juice (freshly squeezed or similar), Other fruit juice ("Fresh up", "Just } \\
\text { Juice"), Soy milk as a drink, Soy milk on cereal or other food, Other milk (goat, rice) as a } \\
\text { drink, Other milk (goat, rice) on cereal or other food, Fruit drinks, Ribena, Cordial, } \\
\text { Sachets, Regular fizzy drinks (lemonade, coke), Diet fizzy drinks (lemonade, coke), Tea } \\
\text { (not herbal), Coffee, Jam or honey, Marmite or vegemite, Nutella, Butter (not in baking), } \\
\text { Margarine (not in baking), Chocolate, Lollies, Fruit leather, Fruit strings fruit roll-ups, } \\
\text { Meat pies, Sausage rolls, Fish fingers or shapes, Battered or crumbed fish, Chicken } \\
\text { nuggets or shapes, Hotdog or fish or sausage from a takeaway shop, Burgers from a } \\
\text { takeaway shop or fast food restaurant, Other item from a takeaway shop or fast food } \\
\text { restaurant, Ready to eat pizza (takeaway shop or supermarket), Kentucky Fried Chicken } \\
\text { or other fried chicken, Subway sandwich, Kebabs or wraps (bought), Sushi (bought), } \\
\text { Chinese, Thai or Indian meal or similar (bought) }\end{array}$ \\
\hline
\end{tabular}

Figure 1. Food groups developed based on their relevance to the gut microbiota. Note: * 'Higher fiber' was defined as $\geq 3.4 \mathrm{~g}$ of dietary fiber which was the median fiber content of the 1010 individual food items reported in the weighed diet records ; 'More healthy' was defined as 'staple foods' with a lower saturated fat and sugar $(<15 \mathrm{~g} / 100 \mathrm{~g})$ content. 


\subsection{Statistical Analysis}

Data were analyzed using Stata statistical software (version 13; StataCorp, College Station, TX, USA). A $p$-value of $p<0.05$ was considered to indicate statistical significance.

The EAT5 FFQ used for the validation analysis was randomly chosen from the first or second FFQ administered. Data reported in the main text uses the 'fruit and vegetable adjusted' EAT5 FFQ values, which were calculated using a weighting factor to adjust the individual fruit and vegetable food items for the participant's overall consumption of fruits and vegetables (see above). Crude EAT5 FFQ values can be found in the supplementary material (Tables S1-S6). Histograms were plotted for each variable and used to visually assess the normality of their distribution. The majority of the distributions were right-skewed so geometric means and $95 \%$ confidence intervals (CI) were used. However, the majority of the distributions of the paired differences were normally distributed. Spearman's correlation coefficients were calculated comparing the FFQ with the WDR. Correlations of 0.30- 0.49 were considered 'acceptable', $0.50-0.70$ 'good' [12], and $>0.70$ were considered 'very good'. The WDR data were adjusted for intra-individual variation using the Multiple Source Method (MSM) program [28] in order to provide a better estimate of 'usual intake'. Cross-classification of WDR and FFQ quartiles was also carried out. The percentage of participants correctly classified was defined as the FFQ categorizing the diet into the same quartile as the WDR, while gross misclassification was defined as the FFQ categorizing the diet into the highest quartile when the WDR was categorized into the lowest quartile, and vice versa. The 'absolute values for surrogate categories' approach determines the extent to which intakes measured using a new method (EAT5 FFQ) reflect intakes measured using a reference method (WDR). Actual values for the surrogate categories [12] were calculated as follows: participants were assigned to quartiles according to intake estimated by the EAT5 FFQ, then the mean intake in each quartile was calculated using the intake determined by the WDR. Regression analyses were calculated to see if there was a trend in the step-wise increases across the quartiles, and the difference in quartile 1 to quartile 4. Bland-Altman analyses [29] were used to assess the agreement between the FFQ and WDR at the individual level.

Intra-class correlation coefficients were calculated comparing the first and second administration of the EAT5 FFQ to assess reproducibility, with correlations of $0.30-0.49$ considered 'acceptable', $0.50-0.70$ 'good' [12], and $>0.70$ 'very good'.

\section{Results}

\subsection{Study Population}

One hundred participants were recruited, of whom 99 parent-child pairs completed the two FFQs and the 3-day WDR. One parent-child pair completed only the first FFQ and the 3-day WDR, meaning that 100 participants were included in the validity analysis and 99 participants in the reproducibility analysis. The 100 young children (44\% male) had a mean (range) age of 5.5 (4.9-6.0) years and BMI of $16.0(13.7-19.7) \mathrm{kg} / \mathrm{m}^{2}$. The participants were mainly of New Zealand European ethnicity $(80 \%)$, with 13\% Māori and 5\% Asian. Half of the participants (49\%) had one sibling, and 31\% more than one. According to the NZDep2013 Index of Deprivation [13], 19\% of the participants were from households in the three most deprived deciles (compared to the expected 30\%).

\subsection{Relative Validity and Reproducibility of Nutrient Intakes}

In general, the 'fruit and vegetable adjusted' FFQ data were closer to the WDR data than the crude unadjusted FFQ data so are used to describe the performance of the EAT5 FFQ. The crude unadjusted figures are presented in the supplementary material (Tables S1-S6).

Table 1 shows the energy and selected nutrient estimates from the EAT5 FFQ compared to the WDR. There were no significant differences in mean carbohydrate, fiber and total NSP intakes measured by the EAT5 FFQ and the WDR. Data comparing the crude EAT5 FFQ and WDR data can be 
found in the supplementary material (Table S1). Estimates of intakes of macro- and micronutrients of less relevance to the gut microbiota can be found in Table S2.

Table 1. Mean daily intake, mean difference, and limits of agreement for selected nutrients of relevance to the gut microbiota according to WDR and EAT5 FFQ in 5-year old children $(n=100)^{1,2}$.

\begin{tabular}{|c|c|c|c|c|c|c|c|c|}
\hline \multirow{2}{*}{ Nutrient } & \multicolumn{2}{|c|}{ WDR } & \multicolumn{2}{|c|}{ EAT5 FFQ } & \multicolumn{4}{|c|}{ EAT5 FFQ vs. WDR } \\
\hline & Mean $^{3}$ & $(95 \% \mathrm{CI})$ & Mean $^{3}$ & $(95 \% \mathrm{CI})$ & Mean Diff & $(95 \% \mathrm{CI})$ & $p^{4}$ & LOA $^{5}$ \\
\hline Energy (kJ) & 5845 & $(5613,6086)$ & 6476 & $(6107,6866)$ & 792 & $(398,1187)$ & $<0.001$ & $-3183-4768$ \\
\hline Fiber $(\mathrm{g})$ & 18 & $(17,19)$ & 19 & $(18,20)$ & 1.2 & $(-0.2,2.6)$ & 0.090 & $-13-15$ \\
\hline Total NSP (g) & 15 & $(14,16)$ & 16 & $(15,17)$ & 0.4 & $(-0.7,1.5)$ & 0.488 & $-11-12$ \\
\hline Soluble NSP (g) & 6.3 & $(5.9,6.6)$ & 8.0 & $(7.4,8.6)$ & 2.0 & $(1.4,2.7)$ & $<0.001$ & $-4.6-8.6$ \\
\hline
\end{tabular}

Bold $=$ not statistically significantly different at $p<0.05$. Abbreviations: CI, confidence interval; diff, difference; LOA, limits of agreement; NSP, non-starch polysaccharides; WDR, weighed diet records. ${ }^{1}$ Data are for the 'fruit and vegetable adjusted' EAT5 FFQ; ${ }^{2}$ FFQ1 or FFQ2 was randomly chosen for each participant; ${ }^{3}$ Geometric mean; ${ }^{4}$ Paired $t$-test; ${ }^{5}$ Bland-Altman limits of agreement [29].

The mean correlation between nutrients measured by the EAT5 FFQ and WDR was 0.34 ('acceptable'), with a range from 0.24 for soluble NSP to 0.38 for total and insoluble NSP (Table 2). The correlations were slightly higher for MSM adjusted values with a mean of 0.35 ('acceptable'). The correlations for the crude EAT5 FFQ and other nutrients can be found in Tables S3 and S4. Table 2 also reports the correlations used to assess reproducibility of the first and second administration of the EAT5 FFQ. The mean correlation was 0.83 ('very good'), with a range from 0.80 to 0.88 . The reproducibility correlations for the crude EAT5 FFQ and other nutrients can be found in Tables S3 and S4.

Table 2. Nutrient correlations between the EAT5 FFQ and WDR $(n=100)$, and reproducibility correlations $(n=99)$ in 5 -year old children ${ }^{1}$.

\begin{tabular}{|c|c|c|c|c|c|}
\hline \multirow[b]{2}{*}{ Nutrient } & \multicolumn{3}{|c|}{ Relative Validity $^{2}$} & \multicolumn{2}{|c|}{ Reproducibility $^{3}$} \\
\hline & EAT5 FFQ ${ }^{4}$ vs. WDR & $\begin{array}{l}\text { MSM Adjusted EAT5 } \\
\text { FFQ }^{5} \text { vs. WDR }\end{array}$ & $\begin{array}{l}\text { Previous } \\
\text { Studies }\end{array}$ & $\begin{array}{l}\text { EAT5 FFQ1 vs. } \\
\text { EAT5 FFQ2 }\end{array}$ & $\begin{array}{l}\text { Previous } \\
\text { Studies }^{7}\end{array}$ \\
\hline Energy (kJ) & 0.32 & 0.32 & $0.19-0.66$ & 0.88 & $0.29-0.73$ \\
\hline Carbohydrate (g) & 0.37 & 0.37 & $0.14-0.66$ & 0.87 & $0.26-0.67$ \\
\hline Fiber $(\mathrm{g})$ & 0.36 & 0.38 & $0.02-0.60$ & 0.80 & $0.26-0.78$ \\
\hline Total NSP (g) & 0.38 & 0.39 & NR & 0.80 & NR \\
\hline Soluble NSP (g) & 0.24 & 0.25 & NR & 0.80 & NR \\
\hline Insoluble NSP (g) & 0.38 & 0.39 & NR & 0.80 & NR \\
\hline
\end{tabular}

Abbreviations: NSP, non-starch polysaccharides; NR, not reported. ${ }^{1}$ Data are for the 'fruit and vegetable adjusted' EAT5 FFQ; ${ }^{2}$ Spearman's correlation coefficients; ${ }^{3}$ Intra-class correlation coefficients; ${ }^{4}$ FFQ1 or FFQ2 was randomly chosen for each participant; ${ }^{5}$ Using Multiple Source Method (MSM) [28] to adjust for the intra-individual variation occurring between the 3 days of diet records; ${ }^{6}$ Inclusion of 12 studies with correlations for nutrients: three Spearman's correlations [30-32], nine Pearson's correlations [33-41]; ${ }^{7}$ Inclusion of 5 studies with correlations for reproducibility for nutrients: one Intra-class correlation coefficients [31], four Pearson's correlations [35,37,39,41].

All nutrients and energy had a percentage correctly classified into quartiles by the EAT5 FFQ and WDR that was greater than chance (25\%), ranging from $28 \%$ (fiber and insoluble NSP) to $36 \%$ (carbohydrate) (Table 3). The mean percentage grossly misclassified was $5.7 \%$ and correctly classified to extreme quartiles was $19.1 \%$ ( $12.5 \%$ would be expected by chance alone). The percentage cross-classifications for the crude EAT5 FFQ and other nutrients can be found in Tables S5 and S6. 
Table 3. Nutrient cross-classification between EAT5 FFQ and WDR quartiles in 5-year old children $(n=100)^{1,2}$.

\begin{tabular}{|c|c|c|c|c|}
\hline \multirow{2}{*}{ Nutrient } & \multicolumn{4}{|c|}{ Cross-Classification } \\
\hline & $\%$ Correctly Classified ${ }^{3}$ & $\%$ Correct \& Adjacent ${ }^{4}$ & $\%$ Grossly Misclassified ${ }^{5}$ & $\%$ Correct Extremes ${ }^{6}$ \\
\hline Chance & $25 \%$ & $62.5 \%$ & $12.5 \%$ & $12.5 \%$ \\
\hline Energy (kJ) & 34 & 79 & 9 & 19 \\
\hline Carbohydrate (g) & 36 & 76 & 6 & 23 \\
\hline Fiber $(\mathrm{g})$ & 28 & 76 & 4 & 18 \\
\hline Total NSP (g) & 29 & 77 & 6 & 18 \\
\hline Soluble NSP (g) & 32 & 69 & 5 & 19 \\
\hline Insoluble NSP (g) & 28 & 76 & 4 & 18 \\
\hline
\end{tabular}

Abbreviations: NSP, non-starch polysaccharides. ${ }^{1}$ Data are for the 'fruit and vegetable adjusted' EAT5 FFQ; ${ }^{2}$ FFQ1 or FFQ2 was randomly chosen for each participant; ${ }^{3} \%$ Correctly classified = percentage of children with WDR and FFQ intakes in the same quartile; $4 \%$ Correct and adjacent = percentage of children with WDR and FFQ intakes in the same and adjacent quartiles; $5 \%$ Grossly misclassified = percentage of children with WDR intakes in the highest quartile and FFQ intakes in the lowest quartile, or vice versa; $6 \%$ Correctly classified to extreme quartiles = percentage of children with WDR and FFQ intakes correctly classified to the lowest and highest quartiles.

Trends for the actual values for surrogate categories show the expected increase across the FFQ quartiles for energy and nutrients (all $p \leq 0.005$ ) (Table 4). The EAT5 FFQ clearly differentiated between the first and fourth quartile for energy and nutrients (all differences between the first and fourth quartile $p \leq 0.011$ ).

Table 4. Ability of the EAT5 FFQ to differentiate between quartiles of WDR intake, determined using actual values for surrogate categories $(n=100)^{1,2}$.

\begin{tabular}{|c|c|c|c|c|c|c|c|}
\hline \multirow{2}{*}{ Nutrient } & \multirow{2}{*}{$\begin{array}{l}\text { Quartiles } \\
\text { Defined by }\end{array}$} & \multicolumn{4}{|c|}{ Mean WDR Intake } & \multirow{2}{*}{$p$ for Trend ${ }^{3}$} & \multirow{2}{*}{$\begin{array}{l}p \text { for } Q 1 \\
\text { vs. Q4 }\end{array}$} \\
\hline & & $Q 1$ & $Q 2$ & Q3 & $Q 4$ & & \\
\hline \multirow{2}{*}{ Energy (kJ) } & EAT5 FFQ & 5414 & 5858 & 6321 & 6262 & \multirow[t]{2}{*}{0.004} & \multirow[t]{2}{*}{0.001} \\
\hline & WDR & 4527 & 5505 & 6346 & 7477 & & \\
\hline \multirow{2}{*}{ Carbohydrate (g) } & EAT5 FFQ & 164 & 186 & 193 & 199 & \multirow[t]{2}{*}{0.002} & \multirow[t]{2}{*}{0.003} \\
\hline & WDR & 132 & 175 & 198 & 238 & & \\
\hline \multirow{2}{*}{ Fiber (g) } & EAT5 FFQ & 16 & 18 & 19 & 21 & \multirow[t]{2}{*}{0.005} & \multirow[t]{2}{*}{0.007} \\
\hline & WDR & 12 & 16 & 20 & 27 & & \\
\hline \multirow{2}{*}{ Total NSP (g) } & EAT5 FFQ & 14 & 15 & 17 & 18 & \multirow[t]{2}{*}{0.001} & \multirow[t]{2}{*}{0.002} \\
\hline & WDR & 10 & 14 & 17 & 23 & & \\
\hline \multirow{2}{*}{ Soluble NSP (g) } & EAT5 FFQ & 5.7 & 6.6 & 6.6 & 7.2 & \multirow[t]{2}{*}{0.001} & \multirow[t]{2}{*}{0.008} \\
\hline & WDR & 4.4 & 5.7 & 6.8 & 9.3 & & \\
\hline \multirow{2}{*}{ Insoluble NSP (g) } & EAT5 FFQ & 8.1 & 9.1 & 9.5 & 11 & \multirow[t]{2}{*}{0.001} & \multirow[t]{2}{*}{0.001} \\
\hline & WDR & 5.7 & 8.2 & 10 & 14 & & \\
\hline
\end{tabular}

Bold = statistically significant difference at $p<0.05$. Abbreviations: NSP, non-starch polysaccharides. ${ }^{1}$ Data are for the 'fruit and vegetable adjusted' EAT5 FFQ; ${ }^{2} \mathrm{FFQ} 1$ or FFQ2 was randomly chosen for each participant; ${ }^{3}$ Significant difference in the trend across the quartiles (regression); ${ }^{4}$ Significant differences between Q1 vs. Q4 (regression).

However, the limits of agreement between the FFQ and the WDR were wide for energy and all five nutrients (Table 1).

Bland-Altman plots show little bias in the EAT5 FFQ with a good scatter seen in the plots of energy and nutrients (Figure 2), although possible overestimation of energy and soluble NSP at higher intakes was indicated. 


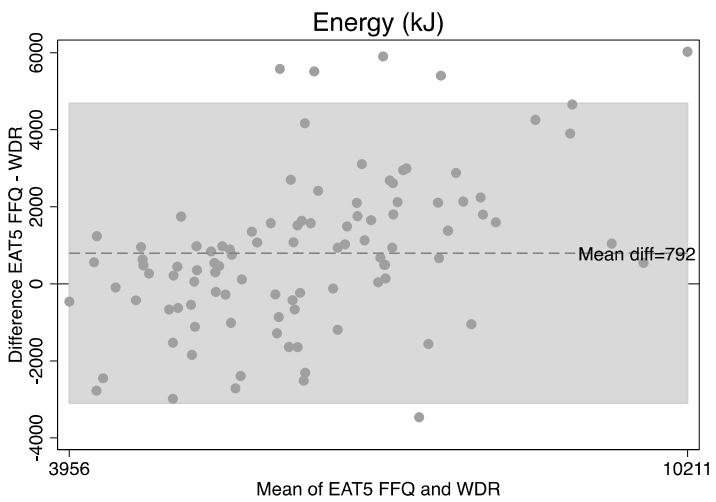

(a)

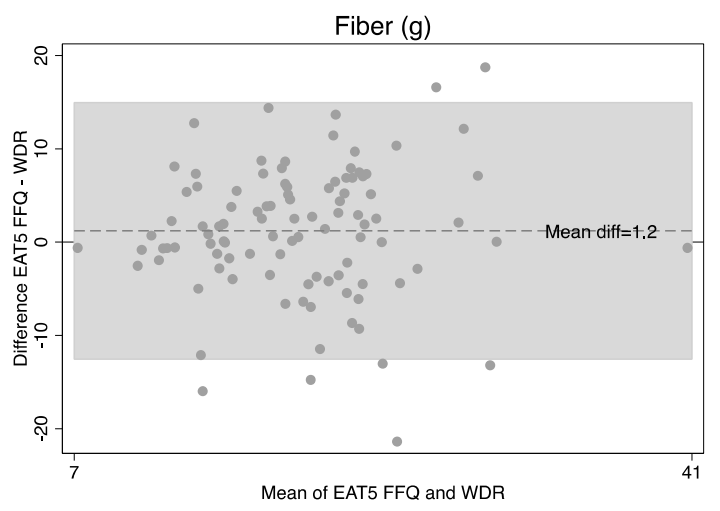

(c)

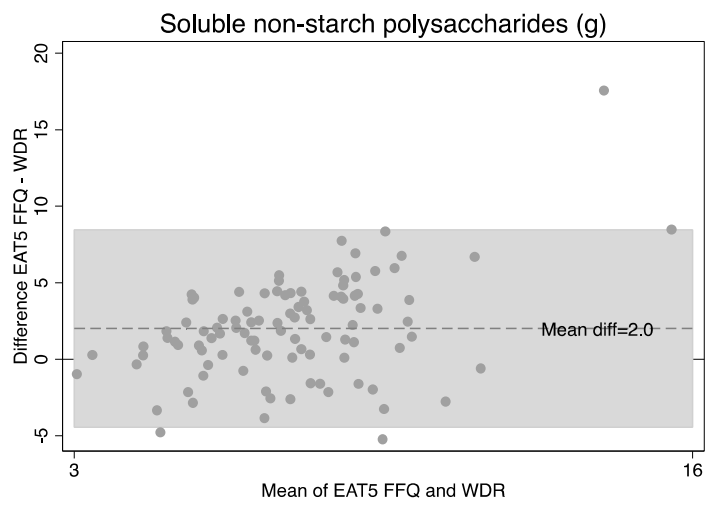

(e)

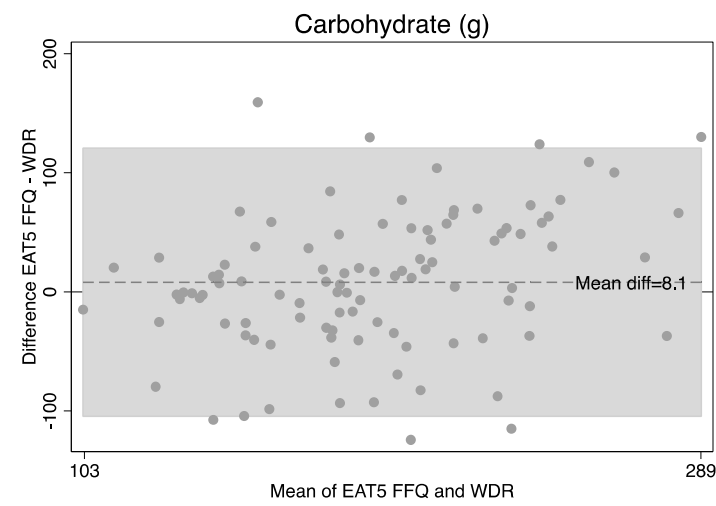

(b)

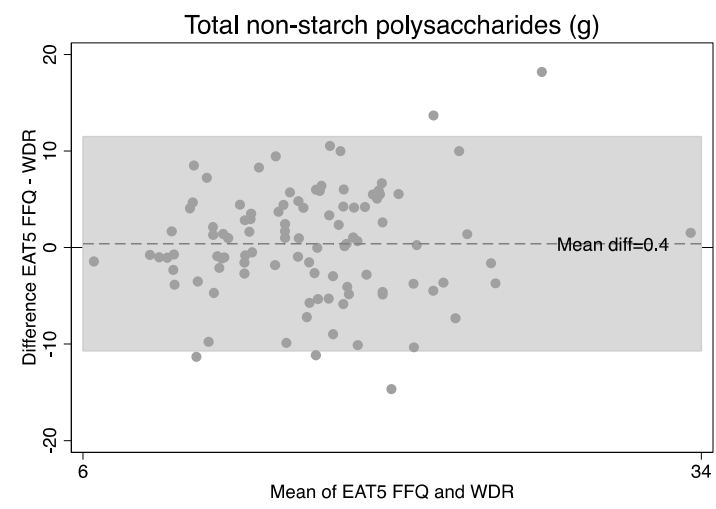

(d)

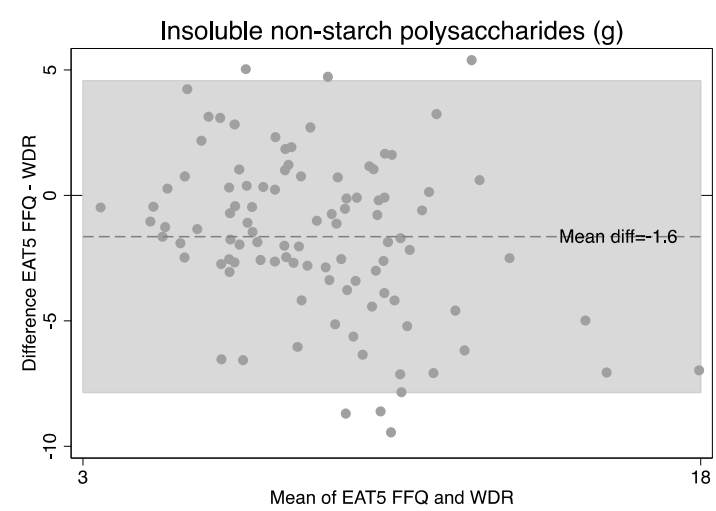

(f)

Figure 2. Bland-Altman plots for nutrient intakes from a randomly chosen FFQ1 or FFQ2 EAT5 FFQ ('fruit and vegetable adjusted') and the weighed diet record (WDR): (a) Energy in kJ; (b) Carbohydrate in grams; (c) Fiber in grams; (d) Total non-starch polysaccharides in grams; (e) Soluble non-starch polysaccharides in grams; and (f) Insoluble non-starch polysaccharides in grams.

\subsection{Relative Validity and Reproducibility of Food Group Intakes}

Table 5 shows the mean energy contribution from each food group for the EAT5 FFQ compared to the WDR. For six of the 12 food groups, the mean EAT5 FFQ intake was not significantly different from the WDR. The other six foods groups gave significantly higher estimates than the WDR. Estimates of intakes of mean amount eaten in grams from each food group can be found in Table S7. 
Table 5. Mean daily intake, mean difference and limits of agreement for food groups (energy contribution) of relevance to the gut microbiota according to WDR and EAT5 FFQ in 5-year old children $(n=100)^{1,2}$.

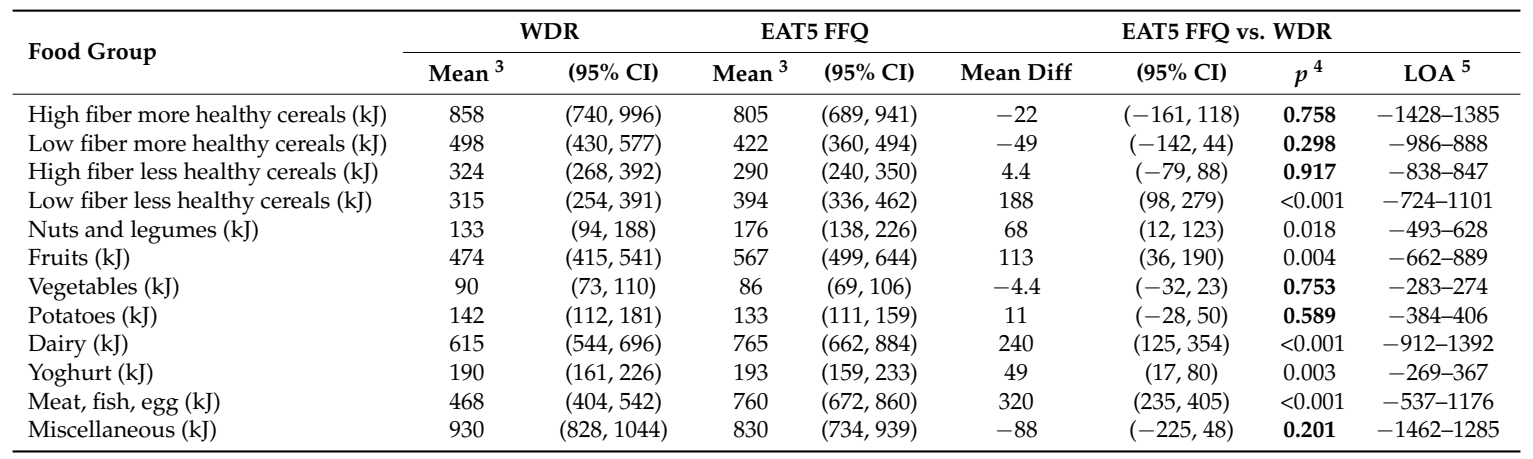

Bold = not statistically significant at $p<0.05$. Abbreviations: CI, confidence interval; diff, difference; LOA, limits of agreement. ${ }^{1}$ Data are for the 'fruit and vegetable adjusted' EAT5 FFQ; ${ }^{2}$ FFQ1 or FFQ2 was randomly chosen for each participant; ${ }^{3}$ Geometric mean; ${ }^{4}$ Paired $t$-test; ${ }^{5}$ Bland-Altman limits of agreement [29].

The mean correlation for food group intakes between the EAT5 FFQ and WDR was 0.41 ('acceptable'), with a range from 0.28 for 'vegetables' and 'miscellaneous' to 0.56 ('good') for 'meat, fish, egg' (Table 6). Table 6 also reports the correlations used to assess reproducibility of the estimates of food group intake for the first and second administration of the EAT5 FFQ. The mean correlation was 0.80 ('very good'), with a range from 0.57 ('potatoes': 'good') to 0.91 ('low fiber more healthy cereals': 'very good'). The relative validity and reproducibility correlations for the amount eaten in grams from each food group can be found in Table S8.

Table 6. Food group (energy contribution) correlations between the EAT5 FFQ and WDR $(n=100)$, and reproducibility correlations $(n=99)$ in 5 -year old children ${ }^{1}$.

\begin{tabular}{|c|c|c|}
\hline \multirow{2}{*}{ Food Group } & Relative Validity $^{2}$ & Reproducibility $^{3}$ \\
\hline & EAT5 FFQ $^{4}$ vs. WDR & EAT5 FFQ1 vs. EAT5 FFQ2 \\
\hline High fiber more healthy cereals (kJ) & 0.37 & 0.84 \\
\hline Low fiber more healthy cereals $(\mathrm{kJ})$ & 0.35 & 0.91 \\
\hline High fiber less healthy cereals (kJ) & 0.38 & 0.80 \\
\hline Low fiber less healthy cereals (kJ) & 0.31 & 0.82 \\
\hline Nuts and legumes cereals (kJ) & 0.45 & 0.69 \\
\hline Fruits $(\mathrm{kJ})$ & 0.42 & 0.83 \\
\hline Vegetables (kJ) & 0.28 & 0.78 \\
\hline Potatoes (kJ) & 0.51 & 0.57 \\
\hline Dairy $(\mathrm{kJ})$ & 0.50 & 0.89 \\
\hline Yoghurt (kJ) & 0.54 & 0.81 \\
\hline Meat, fish, egg (kJ) & 0.56 & 0.83 \\
\hline Miscellaneous (kJ) & 0.28 & 0.84 \\
\hline
\end{tabular}

${ }^{1}$ Data are for the 'fruit and vegetable adjusted' EAT5 FFQ; ${ }^{2}$ Spearman's correlation coefficients; ${ }^{3}$ Intra-class correlation coefficients; ${ }^{4} \mathrm{FFQ} 1$ or FFQ2 was randomly chosen for each participant.

All food groups had a percentage correctly classified into quartiles by the EAT5 FFQ and WDR that was greater than chance (25\%), with a range from $28 \%$ ('vegetables') to $51 \%$ ('meat, fish, egg') (Table 7). The mean percentage grossly misclassified was $5.1 \%$ and correctly classified to extreme quartiles was $22.8 \%$ (12.5\% would be expected by chance alone). The percentage cross-classifications for the amount eaten in grams from each food group can be found in Table S9. 
Table 7. Food group (energy contribution) cross-classifications between EAT5 FFQ and WDR quartiles in 5-year old children $(n=100)^{1,2}$.

\begin{tabular}{|c|c|c|c|c|}
\hline \multirow[b]{2}{*}{ Food Group } & \multicolumn{4}{|c|}{ Cross-Classification } \\
\hline & $\%$ Correctly Classified ${ }^{3}$ & $\%$ Correct \& Adjacent ${ }^{4}$ & $\begin{array}{c}\% \text { Grossly } \\
\text { Misclassified }^{5}\end{array}$ & $\begin{array}{l}\% \text { Correct }^{\circ} \\
\text { Extremes }^{6}\end{array}$ \\
\hline High fiber more healthy cereals $(\mathrm{kJ})$ & 36 & 75 & 5 & 21 \\
\hline Low fiber more healthy cereals $(\mathrm{kJ})$ & 37 & 72 & 5 & 20 \\
\hline High fiber less healthy cereals $(\mathrm{kJ})$ & 33 & 78 & 7 & 22 \\
\hline Fruits $(\mathrm{kJ})$ & 39 & 74 & 5 & 23 \\
\hline Vegetables (kJ) & 28 & 69 & 5 & 17 \\
\hline Potatoes $(\mathrm{kJ})$ & 41 & 82 & 3 & 24 \\
\hline Dairy $(\mathrm{kJ})$ & 42 & 84 & 6 & 24 \\
\hline Yoghurt (kJ) & 47 & 83 & 4 & 29 \\
\hline Meat, fish, egg (kJ) & 51 & 79 & 2 & 29 \\
\hline
\end{tabular}

${ }^{1}$ Data are for the 'fruit and vegetable adjusted' EAT5 FFQ; ${ }^{2}$ FFQ1 or FFQ2 was randomly chosen for each participant;

$3 \%$ Correctly classified = percentage of children with WDR and FFQ intakes in the same quartile; $4 \%$ Correct and adjacent = percentage of children with WDR and FFQ intakes in the same and adjacent quartiles; $5 \%$ Grossly misclassified = percentage of children with WDR intakes in the highest quartile and FFQ intakes in the lowest quartile and vice versa; ${ }^{6} \%$ Correctly classified to extreme quartiles = percentage of children with WDR and FFQ intakes correctly classified to the lowest and highest quartiles.

Trends for the actual values for surrogate categories show the expected increase across the FFQ quartiles for all food groups (all $p \leq 0.028$ ) (Table 8). The EAT5 FFQ clearly differentiated between the first and fourth quartile for all food groups (all differences between the first and fourth quartile $p \leq 0.033)$.

Table 8. Ability of the EAT5 FFQ to differentiate between quartiles of WDR food group intake (energy contribution), determined using actual values for surrogate categories $(n=100)^{1,2}$.

\begin{tabular}{|c|c|c|c|c|c|c|c|}
\hline \multirow{2}{*}{ Food Group } & \multirow{2}{*}{$\begin{array}{l}\text { Quartiles } \\
\text { Defined by }\end{array}$} & \multicolumn{4}{|c|}{ Mean WDR Intake } & \multirow{2}{*}{$p$ for Trend ${ }^{3}$} & \multirow{2}{*}{$p$ for $\mathrm{Q} 1$ vs. $\mathrm{Q} 4^{4}$} \\
\hline & & $Q 1$ & $Q 2$ & $Q 3$ & $Q 4$ & & \\
\hline High fiber more healthy cereals $(\mathrm{kJ})$ & EAT5 FFQ & 719 & 1051 & 1070 & 1347 & $<0.001$ & $<0.001$ \\
\hline \multirow{2}{*}{ Low fiber more healthy cereals (kJ) } & EAT5 FFQ & 431 & 556 & 668 & 781 & \multirow[t]{2}{*}{0.002} & \multirow[t]{2}{*}{0.004} \\
\hline & WDR & 172 & 422 & 642 & 1199 & & \\
\hline \multirow{2}{*}{ Low fiber less healthy cereals $(\mathrm{kJ})$} & EAT5 FFQ & 152 & 334 & 393 & 386 & \multirow[t]{2}{*}{0.028} & \multirow[t]{2}{*}{0.033} \\
\hline & WDR & 0 & 120 & 314 & 856 & & \\
\hline \multirow{2}{*}{ Nuts and legumes (kJ) } & EAT5 FFQ & 76 & 120 & 236 & 424 & \multirow[t]{2}{*}{$<0.001$} & \multirow[t]{2}{*}{$<0.001$} \\
\hline & WDR & 0 & 55 & 199 & 601 & & \\
\hline Fruits $(\mathrm{kJ})$ & EAT5 FFQ & 388 & 576 & 550 & 712 & 0.001 & $<0.001$ \\
\hline \multirow{2}{*}{ Potatoes (kJ) } & EAT5 FFQ & 68 & 136 & 174 & 294 & \multirow[t]{2}{*}{$<0.001$} & \multirow[t]{2}{*}{$<0.001$} \\
\hline & WDR & 1 & 68 & 165 & 439 & & \\
\hline \multirow{2}{*}{ Dairy (kJ) } & EAT5 FFQ & 478 & 606 & 835 & 910 & \multirow[t]{2}{*}{$<0.001$} & \multirow[t]{2}{*}{$<0.001$} \\
\hline & WDR & 257 & 519 & 843 & 1208 & & \\
\hline & EAT5 FFQ & 65 & 138 & 220 & 291 & $<0.001$ & $<0.001$ \\
\hline Yoghurt (kJ) & WDR & 0 & 92 & 215 & 394 & & \\
\hline & EAT5 FFQ & 287 & 574 & 598 & 829 & $<0.001$ & $<0.001$ \\
\hline Meat, tish, egg (kJ) & WDR & 186 & 388 & 621 & 1094 & & \\
\hline & EAT5 FFQ & 849 & 1021 & 1213 & 1213 & 0.010 & 0.021 \\
\hline Miscellaneous (kJ) & WDR & 484 & 854 & 1142 & 1816 & & \\
\hline
\end{tabular}

Bold = Statistically significant difference at $p<0.05 .{ }^{1}$ Data are for the 'fruit and vegetable adjusted' EAT5 FFQ;

${ }^{2}$ FFQ1 or FFQ2 was randomly chosen for each participant; ${ }^{3}$ Significant difference in the trend across the quartiles (regression); ${ }^{4}$ Significant differences between Q1 vs. Q4 (regression). 
However, the limits of agreement were wide for all food group intakes (Table 5).

Bland-Altman plots show some bias in the food group estimates from the EAT5 FFQ with the FFQ having less agreement with the WDR at higher intakes (Figure S1).

\section{Discussion}

The EAT5 FFQ was designed to measure intakes of nutrients and food groups of relevance to the gut microbiota in 5-year old children and showed acceptable validity, and very high reproducibility, for these over a 4-week period. The FFQ provided good estimates of mean intakes of carbohydrate, fiber and total NSP intake, although it tended to overestimate energy (by $14 \%$ ) and soluble NSP (32\%) and underestimate insoluble NSP (by 18\%) compared to the WDR; ranked most intakes acceptably (measured by correlation); and was able to differentiate well between categories of intake. Specifically, the EAT5 FFQ assigned children to correct quartiles of intake well, with very few children being grossly misclassified into the opposite quartile of intake, and was able to clearly differentiate between low and high intakes identified in the WDR.

It is difficult to compare our results directly with the literature given that no FFQs have been validated to specifically measure nutrients and foods of relevance to the gut microbiota in children. However, several validation studies have measured intake of energy and nutrients such as carbohydrate and fiber. The correlations we observed in the current study for these nutrients were within the range of those obtained in previous FFQ validation studies in young children [33,38-42]. Adjusting for usual intake (using MSM) resulted in a small improvement in correlation values. The cross-classification results for energy, carbohydrate and fiber were similar to [31] and better than [39] other FFQ validation studies in young children that have reported these data. Unfortunately, the food group correlations and cross-classifications cannot be compared to previous studies because food groupings depend on the nutrients of focus for the specific validation study, so are different for different studies. However, we believe the FFQ performs well in this context, with correlation values and gross-misclassification values for the food groups being comparable to those obtained for the nutrients in this study.

'Absolute values for surrogate categories' showed the expected stepwise increase for all nutrients and food groups and suggested that the EAT5 FFQ clearly differentiated between highest and lowest quartiles for all nutrients and food groups tested. The 'absolute values for surrogate categories' approach was developed by Willett [12], and although it has not been commonly reported, it has been used in the validation of calcium intakes in children [43] and iron intakes in adults [44]. It is a useful validation tool as it indicates the extent to which an FFQ is able to differentiate between broad categories of intake, as is often required in epidemiological studies.

The reproducibility of the EAT5 FFQ was consistently high, with mean correlations for reproducibility for nutrients of 0.83 and food groups of 0.80 . This was higher than the range of 0.26 to 0.78 that was found for the same nutrients in other FFQ validation studies $[31,39,41]$. Bland-Altman plots for nutrients showed little bias in the EAT5 FFQ with a good scatter seen in the plots, but there was some bias for the food groups, particularly at higher intakes. As expected of an FFQ, the EAT5 FFQ had wide limits of agreement for nutrients and food groups suggesting that it is not appropriate for determining nutrient or food intake in individuals.

This study has several strengths. First, the EAT5 FFQ is the first FFQ validated to measure total, soluble and insoluble NSP intakes, and food groups of relevance to the gut microbiota, in children. The only other studies that have validated FFQs for nutrients of relevance to the gut microbiota (i.e., intake of NSPs [45], dietary fiber [46,47], inulin and oligosaccharides [48]) have been in adults. Interestingly, our study had lower correlations (i.e., they were 'acceptable') than the correlations that were obtained in an adult study, validating intake of NSPs (which were 'acceptable' to 'good') [45]. A possible explanation may be that parental proxy reporting acts as an additional layer of potential error in assessing diets in children. However, the studies validating dietary fiber intake in adults $[46,47]$ also used another questionnaire as the reference method, rather than a diet record. This means that they 
did not use a widely accepted method of dietary assessment with different errors to those of the FFQ as a reference method, as is recommended [49], and as was used in the current study. Second, we aimed to validate several carbohydrate food groups of interest defined by their dietary fiber content and overall healthiness using strict criteria. By contrast, most previous studies have combined all carbohydrate containing foods into a single group such as cereal or grains [16,50] with most of the 'less healthy' carbohydrate foods appearing in the 'snacks' food group, even if they contained fiber [51]. Third, we used a non-consecutive 3-day WDR as the reference method. Many other FFQ validation studies in children used $24-\mathrm{h}$ recalls [31,33,38,39,41,42] or estimated diet records [32], both of which have similar errors to an FFQ with potential for memory lapses and errors in portion size estimation. Finally, cross-check questions were used for the fruit and vegetable sections. Using the cross-check questions improved the performance of the EAT5 FFQ (unadjusted values can be found in the supplementary material). This is particularly important, as the EAT5 FFQ was developed to look at nutrients of relevance to the gut microbiota and hence has a large number of fruit and vegetable questions. Fruit and vegetable food groups have been shown to be commonly over-reported in other FFQ validation studies [18].

Our study has some limitations. First, the ethnicity of the participants is not representative of the New Zealand population as a whole, with a higher proportion of New Zealand Europeans, and an over-representation of participants from the lower and middle deciles of household deprivation. Second, the FFQ was administered only to the primary caregiver, and as the children were five years of age, they would be attending school, so were not with their parents at all times. However, in an effort to overcome this common limitation, parents were asked to report any food and amount eaten if someone else provided their child with food, and the child attended the appointment with their parent so was available for parents to clarify their answers. Third, it was only possible to test the ability of the FFQ to measure intake of fiber and total, soluble and insoluble NSPs, not intake of smaller fiber fractions such as arabinoxylan and pectin that may also impact on the gut microbiota. This was because these fractions are not measured and reported in the New Zealand food composition database, FOODfiles, and the literature was not sufficient to provide reliable data for all 1010 foods consumed in the WDRs.

\section{Conclusions}

In conclusion, the EAT5 FFQ has acceptable validity when compared with a 3-day WDR and has very good reproducibility when measured over four weeks. It is suitable for assessing mean absolute intake of carbohydrate, fiber, and total NSP. The EAT5 FFQ is able to rank the diets of young children adequately, and to correctly assign low and high intakes of nutrients and food groups of relevance to the gut microbiota. The EAT5 FFQ is therefore an appropriate dietary assessment tool for investigating intake of nutrients and food groups of relevance to the gut microbiota in studies of young children.

Supplementary Materials: The following are available online at http:/ /www.mdpi.com/2072-6643/10/11/1627/ s1, Table S1: Mean daily intake, mean difference and limits of agreement for selected nutrients of relevance to the gut microbiota according to WDR and crude EAT5 FFQ in 5-year old children $(n=100)$, Table S2. Mean daily intake, mean difference and limits of agreement for other nutrients according to WDR, crude EAT5 FFQ and 'fruit and vegetable adjusted' EAT5 FFQ in 5-year old children $(n=100)$, Table S3. Nutrients of relevance to the gut microbiota correlations between the crude EAT5 FFQ 1 and WDR $(n=100)$, and reproducibility $(n=99)$ in 5-year old children, Table S4. Other nutrient correlations between the crude EAT5 FFQ and WDR $(n=100)$, and reproducibility $(n=99)$ in 5-year old children, Table S5. Nutrients of relevance to the gut microbiota-cross-classification between the crude EAT5 FFQ and WDR in 5 year old children $(n=100)$, Table S6: Other nutrients cross-classification between the crude EAT5 FFQ and WDR in 5-year old children $(n=100)$. Table S7: Mean daily intake, mean difference and limits of agreement for food groups (in grams) of relevance to the gut microbiota according to WDR and EAT5 FFQ in 5-year old children $(n=100)$. Table S8: Food group (in grams) correlations between the EAT5 FFQ and WDR $(n=100)$, and reproducibility correlations $(n=99)$ in 5-year old children. Table S9: Food group (in grams) cross-classifications between EAT5 FFQ and WDR quartiles in 5-year old children $(n=100)$. Figure S1: Bland-Altman plots of food group intakes (energy contribution) from a randomly chosen FFQ1 or FFQ2 EAT5 FFQ ('fruit and vegetable adjusted') and WDR: (a) High fiber more healthy cereals; (b) Low fiber more healthy cereals; (c) High fiber less healthy cereals; (d) Low fiber less healthy cereals; (e) Fruit; and (f) Vegetables. 
Author Contributions: Conceptualization, R.W.T. and A.-L.M.H.; Data Curation, C.L., R.W.T., J.J.H., E.A.F., and A.-L.M.H.; Formal Analysis, C.L. and J.J.H.; Funding Acquisition, R.W.T. and A.-L.M.H.; Investigation, C.L., H.C., L.K., L.K.C., R.M., R.Y.; Methodology, C.L., R.W.T., J.J.H. and A.-L.M.H.; Project administration, R.W.T. and A.-L.M.H.; Resources, C.L., R.W.T., E.A.F., S.L.C. and A.-L.M.H.; Software, E.A.F.; Supervision, R.W.T. and A.-L.M.H.; Writing-Original Draft Preparation, C.L., R.W.T. and A.-L.M.H.; Writing-Review \& Editing, C.L., R.W.T., J.J.H., G.W.T., E.A.S.-G., E.A.F., S.L.C., H.C., L.K., L.K.C., R.M., R.Y. and A.-L.M.H.

Funding: This research received no external funding.

Acknowledgments: We would like to acknowledge all the families who took part in the EAT5 study, and Gavin Kennedy from University of Otago, New Zealand, for developing the online tool for input of the FFQ data. C.L. was supported by a Doctoral scholarship from the University of Otago.

Conflicts of Interest: The authors declare no conflict of interest. The funders had no role in the design of the study; in the collection, analyses, or interpretation of data; in the writing of the manuscript, and in the decision to publish the results.

\section{References}

1. Clemente, J.C.; Ursell, L.K.; Parfrey, L.W.; Knight, R. The Impact of the Gut Microbiota on Human Health: An Integrative View. Cell 2012, 148, 1258-1270. [CrossRef] [PubMed]

2. Li, J.; Riaz Rajoka, M.S.; Shao, D.; Jiang, C.; Jin, M.; Huang, Q.; Yang, H.; Shi, J. Strategies to increase the efficacy of using gut microbiota for the modulation of obesity. Obes. Rev. 2017, 18, 1260-1271. [CrossRef] [PubMed]

3. Lozzo, P.; Sanguinetti, E. Early Dietary Patterns and Microbiota Development: Still a Way to Go from Descriptive Interactions to Health-Relevant Solutions. Front. Nutr. 2018, 5, 5. [CrossRef]

4. Laursen, M.F.; Bahl, M.I.; Michaelsen, K.F.; Licht, T.R. First Foods and Gut Microbes. Front. Microbiol. 2017, 8, 356. [CrossRef] [PubMed]

5. Flint, H.J.; Duncan, S.H.; Louis, P. The impact of nutrition on intestinal bacterial communities. Curr. Opin. Microbiol. 2017, 38, 59-65. [CrossRef] [PubMed]

6. Tannock, G.W. Understanding Gut Microbiota; John Wiley and Sons: Hoboken, NJ, USA, 2017.

7. Holscher, H.D. Dietary fiber and prebiotics and the gastrointestinal microbiota. Gut Microbes 2017, 8, $172-184$. [CrossRef] [PubMed]

8. Lattimer, J.M.; Haub, M.D. Effects of Dietary Fiber and Its Components on Metabolic Health. Nutrients 2010, 2, 1266-1289. [CrossRef] [PubMed]

9. Leong, C.; Haszard, J.J.; Lawley, B.; Otal, A.; Taylor, R.W.; Szymlek-Gay, E.A.; Fleming, E.A.; Daniels, L.; Fangupo, L.J.; Tannock, G.W.; et al. Mediation analysis as a means of identifying dietary components that affect the fecal microbiota of infants weaned by modified baby-led, compared to traditional, approaches. Appl. Environ. Microbiol. 2018, 84, e00914-18. [CrossRef] [PubMed]

10. Centanni, M.; Hutchison, J.C.; Carnachan, S.M.; Daines, A.M.; Kelly, W.J.; Tannock, G.W.; Sims, I.M. Differential growth of bowel commensal Bacteroides species on plant xylans of differing structural complexity. Carbohydr. Polym. 2017, 157, 1374-1382. [CrossRef] [PubMed]

11. Gibson, R.S. Principles of Nutritional Assessment; Oxford University Press: Oxford, UK, 2005.

12. Willett, W. Nutritional Epidemiology, 2nd ed.; Oxford University Press: Oxford, UK, 1998.

13. Atkinson, J.; Salmond, P.; Crampton, C. NZDep2013 Index of Deprivation; University of Otago: Wellington, New Zealand, 2014.

14. De Onis, M.; Onyango, A.W.; Van den Broeck, J.; Chumlea, C.W.; Martorell, R. Measurement and Standardization Protocols for Anthropometry Used in the Construction of a New International Growth Reference. Food Nutr. Bull. 2004, 25, S27-S36. [CrossRef] [PubMed]

15. Watson, E.O.; Heath, A.-L.M.; Taylor, R.W.; Mills, V.C.; Barris, A.C.; Skidmore, P.M.L. Relative validity and reproducibility of an FFQ to determine nutrient intakes of New Zealand toddlers aged 12-24 months. Public Health Nutr. 2015, 18, 3265-3271. [CrossRef] [PubMed]

16. Mills, V.C.; Skidmore, P.M.L.; Watson, E.O.; Taylor, R.W.; Fleming, E.A.; Heath, A.-L.M. Relative Validity and Reproducibility of a Food Frequency Questionnaire for Identifying the Dietary Patterns of Toddlers in New Zealand. J. Acad. Nutr. Diet. 2015, 115, 551-558. [CrossRef] [PubMed] 
17. Marriott, L.D.; Inskip, H.M.; Borland, S.E.; Godfrey, K.M.; Law, C.M.; Robinson, S.M. What do babies eat? Evaluation of a food frequency questionnaire to assess the diets of infants aged 12 months. Public Health Nutr. 2009, 12, 967-972. [CrossRef] [PubMed]

18. Calvert, C.; Cade, J.; Barrett, J.H.; Woodhouse, A. Using cross-check questions to address the problem of mis-reporting of specific food groups on Food Frequency Questionnaires. Eur. J. Clin.Nutr. 1997, 51, 708-712. [CrossRef] [PubMed]

19. Feskanich, D.; Rimm, E.B.; Giovannucci, E.L.; Colditz, G.A.; Stampfer, M.J.; Litin, L.B.; Willett, W.C. Reproducibility and validity of food intake measurements from a semiquantitative food frequency questionnaire. J. Am. Diet. Assoc. 1993, 93, 790-796. [CrossRef]

20. Mullen, B.J.; Krantzler, N.J.; Grivetti, L.E.; Schutz, H.G.; Meiselman, H.L. Validity of a food frequency questionnaire for the determination of individual food intake. Am. J. Clin. Nutr. 1984, 39, 136-143. [CrossRef] [PubMed]

21. New Zealand Institute for Plant \& Food Research Limited; Ministry of Health New Zealand Food Composition Database. New Zealand FOODfiles ${ }^{\mathrm{TM}}$ 2014. Available online: http:/ / www.foodcomposition. co.nz/foodfiles (accessed on 1 January 2018).

22. New Zealand Institute for Plant \& Food Research Limited; Ministry of Health New Zealand Food Composition Database. New Zealand FOODfiles ${ }^{\mathrm{TM}}$ 2010. Available online: http:/ / www.foodcomposition. co.nz/ foodfiles (accessed on 4 July 2018).

23. Szymlek-Gay, E.A.; Ferguson, E.L.; Heath, A.-L.M.; Fleming, E.A. Quantities of foods consumed by 12-to 24-month-old New Zealand children. Nutr. Diet. 2010, 67, 244-250. [CrossRef]

24. Saeedi, P.; Skeaff, S.A.; Wong, J.E.; Skidmore, P.M.L. Reproducibility and Relative Validity of a Short Food Frequency Questionnaire in 9-10 Year-Old Children. Nutrients 2016, 8, 271. [CrossRef] [PubMed]

25. Singh, R.K.; Chang, H.-W.; Yan, D.; Lee, K.M.; Ucmak, D.; Wong, K.; Abrouk, M.; Farahnik, B.; Nakamura, M.; Zhu, T.H.; et al. Influence of diet on the gut microbiome and implications for human health. J. Transl. Med. 2017, 15, 73. [CrossRef] [PubMed]

26. Sheflin, A.M.; Melby, C.L.; Carbonero, F.; Weir, T.L. Linking dietary patterns with gut microbial composition and function. Gut Microbes 2017, 8, 113-129. [CrossRef] [PubMed]

27. Floyd, F.J.; Widaman, K.F. Factor analysis in the development and refinement of clinical assessment instruments. Psychol. Assess. 1995, 7, 286-299. [CrossRef]

28. Harttig, U.; Haubrock, J.; Knüppel, S.; Boeing, H. The MSM program: Web-based statistics package for estimating usual dietary intake using the Multiple Source Method. Eur. J. Clin. Nutr. 2011, 65, S87. [CrossRef] [PubMed]

29. Bland, J.M.; Altman, D.G. Measuring agreement in method comparison studies. Stat. Methods Med. Res. 1999, 8, 135-160. [CrossRef] [PubMed]

30. Marshall, T.A.; Eichenberger Gilmore, J.M.; Broffitt, B.; Levy, S.M.; Stumbo, P.J. Relative validation of a beverage frequency questionnaire in children ages 6 months through 5 years using 3-day food and beverage diaries. J. Am. Diet. Assoc. 2003, 103, 714-720. [CrossRef] [PubMed]

31. Moghames, P.; Hammami, N.; Hwalla, N.; Yazbeck, N.; Shoaib, H.; Nasreddine, L.; Naja, F. Validity and reliability of a food frequency questionnaire to estimate dietary intake among Lebanese children. Nutr. J. 2016, 15, 4. [CrossRef] [PubMed]

32. Vereecken, C.; Covents, M.; Maes, L. Comparison of a food frequency questionnaire with an online dietary assessment tool for assessing preschool children's dietary intake. J. Hum. Nutr. Diet. 2010, 23, 502-510. [CrossRef] [PubMed]

33. Blum, R.E.; Wei, E.K.; Rockett, H.R.; Langeliers, J.D.; Leppert, J.; Gardner, J.D.; Colditz, G.A. Validation of a food frequency questionnaire in Native American and Caucasian children 1 to 5 years of age. Matern. Child Health J. 1999, 3, 167-172. [CrossRef] [PubMed]

34. Delisle Nyström, C.; Henriksson, H.; Alexandrou, C.; Bergström, A.; Bonn, S.; Bälter, K.; Löf, M. Validation of an Online Food Frequency Questionnaire against Doubly Labelled Water and $24 \mathrm{~h}$ Dietary Recalls in Pre-School Children. Nutrients 2017, 9, 66. [CrossRef] [PubMed]

35. Dennison, B.A.; Jenkins, P.L.; Rockwell, H.L. Development and Validation of an Instrument to Assess Child Dietary Fat Intake. Prev. Med. 2000, 31, 214-224. [CrossRef] [PubMed] 
36. Fumagalli, F.; Pontes Monteiro, J.; Sartorelli, D.S.; Vieira, M.N.C.M.; de Lourdes Pires Bianchi, M. Validation of a food frequency questionnaire for assessing dietary nutrients in Brazilian children 5 to 10 years of age. Nutrition 2008, 24, 427-432. [CrossRef] [PubMed]

37. Kobayashi, T.; Kamimura, M.; Imai, S.; Toji, C.; Okamoto, N.; Fukui, M.; Date, C. Reproducibility and validity of the food frequency questionnaire for estimating habitual dietary intake in children and adolescents. Nutr. J. 2011, 10, 27. [CrossRef] [PubMed]

38. Matos, S.M.A.; Prado, M.S.; Santos, C.A.S.T.; D’Innocenzo, S.; Assis, A.M.O.; Dourado, L.S.; Oliveira, N.S.; Rodrigues, L.C.; Barreto, M.L. Validation of a food frequency questionnaire for children and adolescents aged 4 to 11 years living in Salvador, Bahia. Nutr Hosp. 2012, 27, 1114-1119. [CrossRef] [PubMed]

39. Rodriguez, C.A.; Smith, E.R.; Villamor, E.; Zavaleta, N.; Respicio-Torres, G.; Contreras, C.; Perea, S.; Jimenez, J.; Tintaya, K.; Lecca, L.; et al. Development and validation of a food frequency questionnaire to estimate intake among children and adolescents in Urban Peru. Nutrients 2017, 9, 1121. [CrossRef] [PubMed]

40. Stein, A.D.; Shea, S.; Basch, C.E.; Contento, I.R.; Zyberf, P. Consistency of the willett semiquantitative food frequency questionnaire and 24-hour dietary recalls in estimating nutrient intakes of preschool children. Am. J. Epidemiol. 1992, 135, 667-677. [CrossRef] [PubMed]

41. Vioque, J.; Gimenez-Monzo, D.; Navarrete-Muñoz, E.M.; Garcia-de-la-Hera, M.; Gonzalez-Palacios, S.; Rebagliato, M.; Ballester, F.; Murcia, M.; Iñiguez, C.; Granado, F.; et al. Reproducibility and Validity of a Food Frequency Questionnaire Designed to Assess Diet in Children Aged 4-5 Years. PLoS ONE 2016, 11, e0167338. [CrossRef] [PubMed]

42. Parrish, L.A.; Marshall, J.A.; Krebs, N.F.; Rewers, M.; Norris, J.M. Validation of a food frequency questionnaire in preschool children. Epidemiology 2003, 14, 213-217. [CrossRef] [PubMed]

43. Taylor, R.W.; Goulding, A. Validation of a short food frequency questionnaire to assess calcium intake in children aged 3 to 6 years. Eur. J. Clin. Nutr. 1998, 52, 464-465. [CrossRef] [PubMed]

44. Heath, A.-L.M.; Skeaff, C.M.; Gibson, R.S. The relative validity of a computerized food frequency questionnaire for estimating intake of dietary iron and its absorption modifiers. Eur. J. Clin. Nutr. 2000, 54, 592-599. [CrossRef] [PubMed]

45. Emmett, P.; Symes, C.; Braddon, F.; Heaton, K. Validation of a new questionnaire for assessing habitual intake of starch, non-starch polysaccharides, sugars and alcohol. J. Hum. Nutr. Diet. 1992, 5, 245-253. [CrossRef]

46. Healey, G.; Brough, L.; Murphy, R.; Hedderley, D.; Butts, C.; Coad, J. Validity and Reproducibility of a Habitual Dietary Fibre Intake Short Food Frequency Questionnaire. Nutrients 2016, 8, 558. [CrossRef] [PubMed]

47. Reeves, M.M.; Winkler, E.A.H.; Eakin, E.G. Fat and fibre behaviour questionnaire: Reliability, relative validity and responsiveness to change in Australian adults with type 2 diabetes and/or hypertension. Nutr. Diet. 2015, 72, 368-376. [CrossRef]

48. Dunn, S.; Datta, A.; Kallis, S.; Law, E.; Myers, C.E.; Whelan, K. Validation of a food frequency questionnaire to measure intakes of inulin and oligofructose. Eur. J. Clin. Nutr. 2011, 65, 402-408. [CrossRef] [PubMed]

49. Cade, J.; Thompson, R.; Burley, V.; Warm, D. Development, validation and utilisation of food-frequency questionnaires-A review. Public Health Nutr. 2007, 5, 567-587. [CrossRef] [PubMed]

50. Huybrechts, I.; De Backer, G.; De Bacquer, D.; Maes, L.; De Henauw, S. Relative Validity and Reproducibility of a Food-Frequency Questionnaire for Estimating Food Intakes among Flemish Preschoolers. Int. J. Environ. Res. Public Health 2009, 6, 382-399. [CrossRef] [PubMed]

51. Flood, V.M.; Wen, L.M.; Hardy, L.L.; Rissel, C.; Simpson, J.M.; Baur, L.A. Reliability and validity of a short FFQ for assessing the dietary habits of 2-5-year-old children, Sydney, Australia. Public Health Nutr. 2013, 17, 498-509. [CrossRef] [PubMed]

(C) 2018 by the authors. Licensee MDPI, Basel, Switzerland. This article is an open access article distributed under the terms and conditions of the Creative Commons Attribution (CC BY) license (http:/ / creativecommons.org/licenses/by/4.0/). 